\title{
Liturgical Inculturation for Tsonga Widows' Mourning Rituals
}

\author{
Hundzukani Portia Khosa-Nkatini
}

\section{Introduction}

This study on Tsonga widows' mourning rituals was done in a village in Giyani, Limpopo. The research was based on the observation of the exclusion of widows from church attendance and activities in the Evangelical Presbyterian Church in South Africa (EPCSA). The study was conducted among Tsongaspeaking widows in the Tsonga community. The exclusion of widows is respected and understood by members of the church, because they believe in respecting people's cultural and traditional beliefs. The study attempted to examine the conflict between Christianity and Tsonga mourning rituals and practices in the EPCSA. This was a qualitative study; however, a literature review was also included.

Mourning rituals were presented and analyzed in an to attempt to find ways in which practical theology can help the Tsonga widows in the EPCSA through liturgical inculturation as they undergo the mourning period. The study consisted of data on mourning rituals collected from six individual widows and a focus group consisting of seven widows. The collected data was analyzed and interpreted to study the conflict between cultural practices regarding death and mourning and Christianity in the EPCSA. According to Tsonga cultural tradition, the rituals designed for Tsonga widows are not meant to harm widows or women but rather to protect them. Mourning ritual practices are common in most African cultures. These widowhood practices vary widely in different countries and among different tribes.

Currently, there is a liturgical hiatus concerning rituals of mourning for widows in the EPCSA in Tsonga culture: that is, the EPCSA has not yet produced any guidelines on how these rituals interact with EPCSA liturgical practices. It is believed that most widows who partake in such rituals are compelled to earn the respect of their in-laws and the community and to be accepted by the ancestors of the family. Differing views among scholars continue to contribute to the conflict between Christianity and African ritual practices.

\section{Methodology}

The research methodology involved both a study of literature and qualitative empirical work in the form of interviews of individuals and a focus group comprised of Tsonga widows. This qualitative re-

* The thesis was accepted by the Faculty of Theology \& Religion, University of Pretoria, Hatfield, South Africa. Supervisor: prof. dr. Cas Wepener. Co-supervisor: prof. dr. Esias Meyer.

E-mail: hundzukhosa@gmail.com. 
search stressed the socially constructed nature of the reality that Tsonga widows face in their widowhood and rituals that they are exposed to during their twelve-month mourning period. Data was collected using the following methods.

\subsection{Semi-structured interviews and questions}

Semi-structured interviews consist of several key questions that help to define the areas to be explored, but also allow the interviewer or interviewee to diverge in order to pursue an idea or response in more detail. This method is a one-on-one method of collecting data. These may take place in a faceto-face setting or over the telephone or the internet. For this study the interviews were conducted face to face, and voice recordings of the interviews were made.

\subsubsection{Individuals interviews}

The individual interviews were semi-structured interviews, which allowed the discussion to be open and free. The researcher's follow-up questions were based on the interviewee's response in line with the research questions and research topic. The interview structure allowed narratives by the widows because they were free to engage openly about what they felt would be helpful to the study with regard to widowhood practices. The written questions served as a guideline to aid participants in where they could start narrating their journey as widows.

\subsubsection{Focus group (6-10 people)}

Focus groups are used for generating information on collective views and the meanings that lie behind those views. In this study, the focus group interviews involved open-ended questions based on the research topic. The participants were asked to elaborate and follow up questions were asked and permitted to be asked. The author used the following participants for the individual group: Tinyiko, Sarah, Ntsako, Grace, Rhandzu and Nkateko. The focus group used the following participants: Stella, Cathy, Grace, Kokwana Sithole, Reagan, Thandi and Maria.

\section{The Evangelical Presbyterian Church in South Africa and Tsonga widows' mourning rituals}

In this context, the researcher focused on bereavement within the Tsonga culture for Christians, with special given to the EPCSA family. Bereavements differ from culture to culture; it also differs from family to family. In African culture, rituals are a very sensitive issue, as it is part of who people are, part of their pride as African people. VaTsonga people esteem ancestors as playing a vital role in their lives. They see death as a way for life here on earth to end and to begin eternal life. In this way they join their family tribe as ancestors. To the Tsonga people, when a person's life ends here on earth, it is believed 
that rituals must be done so the ancestors can welcome a new member to the ancestral tribe. Failure to do so means the spirit of that person will fly around the house and there will be no peace in the family. Widows therefore need to submit to particular rituals and a range of strict prescriptions for the duration of the mourning period.

In the EPCSA, when a member of the church dies, church elders formally inform the minister of the death. The minister, in the company of the church elders, is expected to visit the family to conduct a short prayer and informs the family that the church is aware of the death in the family. From there on, there will be daily evening prayer services at the family's home. I observed that widows are absent from these evening prayers. They are usually in the bedroom, sitting on the mattress covered in blankets as part of mourning rites. This means they are not part of the evening services and sermons that are meant to comfort the family of the deceased.

There are many beliefs and rituals surrounding widowhood; women only get to know about them when they become widows. If a woman were to ask what would be expected of her if she became a widow, she would be immediately suspected of planning her husband's death. There are different rites and rituals conducted before the husband is buried and after he has been buried, leading up to the time of the cleansing ceremony.

In the course of this research, I asked whether there was a way in which Christianity and Africanism could come together and complement each other. One of the respondents answered:

I think the church must give the family their space, because if the church is there, the family will not be free to perform their rituals and some of these rituals are not for public eyes. Even some of the family members will not be aware of it until they are widows themselves - that's how things are done (Cathy).

Some widows go through these rituals because they are afraid of what might happen if they do not, as many taboos are related to not following the rituals. As one respondent said, "There are rules that we are given as widows. These rules are too heavy, some of them we cannot tell you. If a widow fails to do all the rituals, she will suffer a lot in life ... a lot" (Kokwana Sithole). This belief is true for many of the respondents. These rituals are acceptable to others because they believe it is part of who they are as Tsonga women.

There is a relationship between the EPCSA and cultural beliefs. It is not a close relationship, but rather a relationship of respect, which allows the church to do its part and the family theirs during the funeral and mourning period. This might be misinterpreted as 'silence' by the church during the time these widows need them the most, especially the widows who do not wish to practice the cultural mourning rituals but are afraid to refuse because they have no one to support them in that decision. $A$ general description of these rituals will be given in the next section. This general description was collected from the empirical work. 


\section{General description of Tsonga widows' mourning rituals}

Sarah narrated how she was taken to a nearby river and given an egg by the elders. The elders then instructed her to break the egg using her thighs, meaning that she needed to squeeze her thighs as hard as possible to break the egg placed between them. If she had failed to break or crack the egg between her thighs, the elders would label her as having a hand in or knowing how her late husband passed on, regardless of the cause of death. After successfully breaking the egg, she was then instructed to jump over the fire. Should the fire burn her, it was said that it would be a sign that her late husband's ancestors were angry at her for killing her husband.

Cathy had to eat and drink from a specific plate and cup throughout her twelve-month mourning period. She was not allowed to share a plate with anyone, as it might bring bad luck to the person sharing a plate with her. She was not allowed to use a hand to discipline her children as it might bring bad luck to her children. When she was greeted on the street, she had to kneel and respond slowly with her hand faced down regardless of the age of the person greeting her. She was not allowed to shout or scream, as that might be interpreted as excitement about her husband's death.

Thandi was also taken to a nearby river, where she was told to put out a burning fire using her urine. After putting the fire out, the elders (women) took a razor and cut her vulva until she started bleeding and blood dripped between her thighs. This was done to purge her husband's blood from her body. Stella, like the rest of the participants, also wore black clothes for a year as a sign of grief. At the end of the mourning period, the traditional healer was brought back to do the final cleansing rituals. Muti (a herb) was also thrown all over the house and yard again to let the husband's spirit finally rest in peace. She was given muti to put in her food to eat and different muti to put in her water to bath in it. When Reagan heard of her husband's death, she was not allowed to drink water the whole day because it was taboo. She was told that if she drank water, she would go deaf. These are just some of the rites and practices that the participants had to undergo in the traditional mourning of their husbands.

Nkateko's husband was a traditional healer. He had three wives, including her. Nkateko and the other wives were not allowed to attend church; their husband did not allow them to. She only became a church member after her husband's death. Their children were allowed to attend church. After he died, she and the other wives sat on a grass mat; she said a considerable number of people came to support them because her husband had helped a lot of people. She seemed very surprised that I did not know her husband or had ever heard of him, because according to her, he was a very powerful man and known for helping many with their problems through muti. She said a lot of teachers, police officers, and women all over Limpopo used his services. She said her husband's death was caused by jealousy: other traditional healers used black magic to kill him.

Rhandzu believes that it is very important for every widow to do this, as it shows respect both for your late husband and for tradition. I asked if there was anything she would not have done or 
changed with regard to the mourning rituals she underwent or any experience she went through. She said she would not change anything because that is how things should be done and added that, should a woman be working, she should take a year off work to mourn her husband properly. She added that as long as there is meat and pap in the house for the widow to eat at her in-laws', there are no reasons for her to rush back to work in the city. She argued that work and money were less important compared to mourning your husband. If a woman does not mourn her husband properly, she will bring bad luck not only to herself but to her whole family.

Some of the rules they were given included the following. They were not allowed to visit anyone. They were not allowed to have any sexual relationships until the mourning period has come to an end. They were not allowed to cook food for other people as it might invite death to those who eat the food. They were not allowed to go to church for the first three months; after the three months, if they went to church they were told to sit in the back during the service.

\section{Data analysis}

Research participants were widows between the ages of twenty-five and seventy, who live in a village in Giyani, in Limpopo, and were members of the EPCSA during the time of this study. I used Python to process the given data and obtained some statistics from the analyzed data. I was also able to perform the most frequent word analysis and popular noun phrase analysis on each of the interviews and title responses, respectively. This program can also perform sentiment analysis and find popular verbs. At the end of this step, I had twelve lists, two for each of the six interviews, listing all dialogue spoken by the interviewer and the subject independently. I used the thematic analysis as a qualitative analysis that is used in empirical studies. It is the process of identifying patterns within qualitative data.

\subsection{Themes from individual interviews and the focus group}

The following themes were found in the transcripts: namely, patriarchy, exclusion/inclusion, rites and rituals, clean and unclean, mattress and mourning, and church and culture. These themes were found after looking at the data in both types of interviews: the focus group and the individual interviews. Afterwards, a process of thematic coding was followed.

\subsubsection{Patriarchy}

Most of the participants shared the rules that they received during their mourning period, which limited not only their movements but also how they expressed themselves or behaved as widows. According to one of the participants, pseudonym Pam, some of these rituals involve a widow performing naked in the presence of female elders. Tinyiko narrated how she had to jump over a fire. Ntsako explained some of her duties as a widow, which included jumping over a fire and breaking an egg with her thighs. 
These mourning rituals are performed only by widows, and it can be argued that they are oppressive to women. Some women choose to do all the mourning rituals because it is expected of them as Tsonga widows. Most of the widows did not experience these rituals as oppressive but simply as a part of their culture. However, I looked at these practices as an outsider and observed that these rituals are oppressive and part of the larger system of patriarchy.

Many women in Africa believe that they should not question culture and tradition but should do as they are told. Women remain silent in the name of respecting culture and their in-laws. When the participants were asked if the men also mourn, these were some the responses:

Let us not lie, let's be honest - they don't mourn. Let me tell you the truth, I once saw a young man who lost his wife. They did a ritual for him immediately after his wife's death so he could move on. They even encouraged him to find another wife after two months, saying it is not good for a man to be alone. That is the reason I sometimes do not understand these mourning things; it's confusing (Cathy).

Mourning is for women, not men (Stella).

In the Tsonga culture this is true; most of these rituals widows have to undergo are done by other women to widows. Making the fire that widows are expected to jump over, bathing the widows in the river, and other ritual practices are all administered by female elders in the community. These women who ensure widows do the rituals the right way do not see anything wrong with these rituals because it has always been done and has been passed on to them from generation to generation. It is not seen as any form of abuse or oppression, but as a cultural practice that has never harmed anyone. It is thus also women who participate in upholding forms of patriarchy by means of rituals. The issue around women's rights and cultural practices remains a debate among ministers in the EPCSA and even among scholars.

\subsubsection{Exclusion/inclusion}

Wearing black clothes while mourning is an African cultural custom that suggests the emotional state of the widow regarding the deceased husband. When I asked the participants to explain why a widow must wear black clothes for a year, one of the respondents argued that, "It shows that you are hurt by the death of your husband" (Stella). The mourning period, which differs according to various cultures, would be for a period of twelve months. This is supported by several of the respondents: "Yes, you wear black clothes for a full twelve months. At the end of the period, a ceremony is done to end the mourning period. Thereafter a widow can wear any clothes of her choice" (Stella). It is evident that the rituals have been passed on from one generation to the other and that no one has ever questioned these rituals. One of the participants argued that they had a problem with having to wear black 
clothes, as it interfered with their way of life and they were discriminated against because some community members held negative views toward mourning widows. For example, it makes it difficult for the widow to take public transport.

\subsubsection{Clean/unclean}

Throughout the mourning period there were items that were only used by the widows and could not be used by anyone else. Afterward these items were discarded. For example, the cups they used to drink from are either thrown away or burnt. Even the mat they sat on during the mourning period must be burnt because if children were to sit on it, it would bring bad luck to them. Some participants felt it was a disgrace how some widows have no respect: for example, they do not mourn for twelve months, they do not wear black mourning garments, and they wear bright colors. One participant referred to such behavior as a disgrace.

When asked to explain what Makhuma was, one of the participants compared it to being HIV positive, with many physical symptoms resembling those of AIDS. Makhuma is what happens to a woman when she fail to respect the mourning period or to a man who has sex with a widow before the end of her mourning period, therefore strictly upholding the notion of the widow's uncleanness during her mourning period. Makhuma can reportedly only be healed by a skilled traditional healer, which makes it a significant deterrent.

\subsubsection{Ritual space}

As mentioned earlier, a relative informs the widow that her husband has passed away and she is then immediately expected to enter the ritual space of sitting on a mattress on the floor. Following separation, there are changes from the normal routine of daily life; the transition period is a period in which there will be a great deal of uncertainty and mystery that causes much anxiety. In this study there is a change for a woman from being a woman to being a widow and having to undergo certain ritual practices that require ritual space.

The participants all experienced widowhood and had to go through mourning rituals that were designed for them by their in-laws. Every widow narrated the experience differently. The widows were all Tsonga widows but went through different rituals, although there were some similarities. It can be argued that not all Tsonga widows go through the same cultural rituals. It would be an injustice if one were to read this study and conclude that all Tsonga widows or African widows are going through the rituals documented in this study. Even some of the older widows performed the rituals simply because it was a custom that had to be followed, though they did not say what justified the performance of the rituals. The older widows are not pleased with all these changes and feel that restoration of the ritual to the original form is essential but do not discuss the implications of not doing so. According to some participants, mourning rituals are part of the healing process, especially among those who believe in 
the healing value of the mourning rituals. The mourning for men and women is different in the Tsonga culture; women are expected to cry and mourn for their husbands, while men are expected to be 'men' about it and move on.

\section{Conclusion}

Widows' mourning rituals are also administered to members belonging to the EPCSA. It appears that EPCSA has not yet produced a guideline on how these rituals interact with EPCSA liturgical practices. Due to the current liturgical hiatus with regard to liturgical rituals relating to mourning practices for widows within the EPCSA under the Tsonga culture, it is also apparent that there is a need for a thorough practical theological critique on the existing ritual practices.

Liturgical rituals can be inculturated in the EPCSA in order to assist widows in their mourning period. This liturgy should be designed by the church's liturgy committee, also taking into consideration the findings in this study. Liturgical inculturation that goes deeper than merely so-called cultural aspects such as liturgical dress or Eucharistic elements and that truly engages with an African worldview of the spirit world will result in an inculturated liturgy that is empowering for those who participate in it. 